\title{
PENGARUH KECERDASAN EMOSIONAL, KECERDASAN SPIRITUAL, PERILAKU BELAJAR, DAN LINGKUNGAN BELAJAR TERHADAP TINGKAT PEMAHAMAN AKUNTANSI DENGAN PERKEMBANGAN TEKNOLOGI SEBAGAI VARIABEL PEMODERASI
}

\author{
Meitha Tyas Utami \\ Sumaryanto
}

\begin{abstract}
The level of student understanding of accounting is not only measured by the intelligence but also the emotional intelligence can be measured, spiritual intelligence, learning behavior, and the learning environment in this study is an independent variable. While the dependent variable is the level of understanding of accounting. Added moderating variable is the development of technology. The study sample of 180 accounting students UGM, STIE YKPN, UPN Veteran Yogyakarta, and UAD taken using purposive sampling technique. Data analysis techniques used in this study is a linear regression, moderated regression analysis, and the Chow test. Result of research indicate that emotional intelligence, spiritual intelligence, behavioral learning, and the learning environment does not affect the level of understanding of accounting, which means that the hypothesis first, second, third, and fourth is unacceptable. In addition, the MRA test results and test results show that the Chow technological developments do not strengthen the relationship between emotional intelligence, spiritual intelligence, behavioral learning, and the learning environment to the level of understanding of accounting, which means that the hypothesis fifth, sixth, seventh, and eighth is not acceptable.
\end{abstract}

Keywords: emotional intelligence, spiritual intelligence, behavioral learning, learning environment, the level of understanding of accounting, and technology development.

\section{PENDAHULUAN}

Kebanyakan orang menjadikan kecerdasan intelektual (IQ) sebagai dasar penilaian kecerdasan seseorang. Sistem pendidikan juga selalu menekankan pentingnya nilai akademik atau IQ saja. Sedangkan ada kecerdasan emosional (EQ) dan kecerdasan spiritual (SQ) yang juga dapat dijadikan sebagai dasar penilaian kecerdasan. Selain kecerdasan emosional (EQ) dan kecerdasan spiritual (SQ), perilaku belajar yang juga menjadi faktor pendorong prestasi akademik mahasiswa. Penelitian ini menambahkan variabel perkembangan teknologi sebagai variabel pemoderasi sebagai pembeda dari penelitian terdahulu. 
Penelitian ini terinspirasi dari penelitian sebelumnya yang dilakukan oleh Rachmi (2010) tentang pengaruh kecerdasan emosional, kecerdasan spiritual, dan perilaku belajar terhadap tingkat pemahaman akuntansi, Yuniani (2010) dan Trisniwati (2003) tentang pengaruh kecerdasan emosional terhadap tingkat pemahaman akuntansi, Yani (2012) tentang pengaruh kecerdasan intelektual, kecerdasan emosional, dan kecerdasan spiritual terhadap pemahaman akuntansi, serta penelitian Maryati (2012) tentang pengaruh motivasi belajar, gaya belajar, dan perilaku belajar terhadap tingkat pemahaman akuntansi. Peneliti menggabungkan beberapa variabel dari peneliti terdahulu dan menambahkan variabel baru untuk kemudian diteliti guna apakah variabel tersebut berpengaruh terhadap tingkat pemahaman akuntansi. Berdasar uraian yang telah dijelaskan maka tujuan dari penelitian ini adalah untuk mengetahui pengaruh kecerdasan emosional, kecerdasan spiritual, perilaku belajar, dan lingkungan belajar terhadap tingkat pemahaman akuntansi yang diperkuat dengan perkembangan teknologi sebagai variabel pemoderasi.

\section{TINJAUAN PUSTAKA}

\section{Kecerdasan Emosional}

Menurut Goleman (2000) dalam Trisniwati (2003), kecerdasan emosional adalah kemampuan untuk mengenal perasaan diri sendiri dan orang lain untuk memotivasi diri sendiri dan mengelola emosi dengan baik dalam diri kita dan hubungan kita. Kemampuan ini saling berbeda dan melengkapi dengan kemampuan akademik murni, yaitu kemampuan kognitif murni yang diukur dengan IQ. Goleman (2005: 513) membagi kecerdasan emosional menjadi lima bagian yaitu tiga komponen kompetensi emosional dan dua komponen kompetensi sosial. Lima komponen tersebut adalah:

a) Kesadaran diri, merupakan kemampuan seseorang untuk mengetahui perasaan dalam dirinya dan digunakan untuk membuat keputusan bagi diri sendiri.

b) Pengaturan diri, adalah kemampuan menangani emosi diri sehingga berdampak positif pada pelaksanaan tugas, peka terhadap kata hati dan sanggup menunda 
kenikmatan sebelum tercapainya suatu sasaran, mampu segera pulih dari tekanan emosi.

c) Motivasi, adalah kemampuan menggunakan keinginan yang paling dalam untuk menggerakkan dan menuntun seseorang menuju sasaran, membantu seseorang dalam mengambil inisiatif dan bertindak sangat efektif, dan untuk bertahan menghadapi kegagalan dan frustasi.

d) Empati, adalah kemampuan merasakan apa yang dirasakan oleh orang lain. Mampu memahami perspektif orang lain dan menimbulkan hubungan saling percaya, serta mampu menyelaraskan diri dengan berbagai tipe individu.

e) Keterampilan sosial, adalah kemampuan menangani emosi dengan baik ketika berhubungan dengan orang lain dan dengan cermat membaca situasi dan jaringan sosial, berinteraksi dengan lancar, menggunakan keterampilanketerampilan ini untuk memimpin, bermusyawarah, dan bekerjasama dalam tim. $\mathrm{H}_{1}=$ Kecerdasan spiritual berpengaruh terhadap tingkat pemahaman akuntansi. $\mathrm{H}_{5}=$ Perkembangan teknologi memperkuat hubungan antara kecerdasan emosional terhadap tingkat pemahaman akuntansi.

\section{Kecerdasan Spiritual}

Agustian (2005: 47) menjelaskan bahwa kecerdasan spiritual berisi suara hati, dan hati adalah bagian dari aspek spiritualitas. Kecerdasan spiritual adalah kemampuan untuk memberi makna spiritual terhadap pemikiran, perilaku dan kegiatan, serta mampu mensinergikan IQ, EQ dan SQ secara komprehensif. SQ memberi kita rasa moral, kemampuan menyesuaikan aturan yang kaku dibarengi dengan pemahaman dan cinta serta kemampuan setara untuk melihat kapan cinta dan pemahaman sampai pada batasannya (Zohar dan Marshall, 2001: 5).

$\mathrm{H}_{2}=$ Kecerdasan spiritual berpengaruh terhadap tingkat pemahaman akuntansi.

$\mathrm{H}_{6}=$ Perkembangan teknologi memperkuat hubungan antara kecerdasan spiritual terhadap tingkat pemahaman akuntansi.

\section{Perilaku Belajar}

Perilaku belajar mencakup cara belajar dan kebiasaan belajar seseorang. Perilaku belajar akan berpengaruh pada prestasi belajar yang diraih. Jika perilaku 
belajar baik maka prestasi belajar akan baik, sebaliknya jika perilaku belajar buruk maka prestasi belajar juga tidak akan maksimal. Ada empat perilaku belajar yang baik menurut Suwardjono (2004) dalam Rachmi (2010), yaitu kebiasaan mengikuti pelajaran, kebiasaan membaca buku, kunjungan ke perpustakaan, dan kebiasaan menghadapi ujian.

$\mathrm{H}_{3}=$ Perilaku belajar berpengaruh terhadap tingkat pemahaman akuntansi.

$\mathrm{H}_{7}=$ Perkembangan teknologi memperkuat hubungan antara perilaku belajar terhadap tingkat pemahaman akuntansi.

\section{Lingkungan Belajar}

Menurut Saroni (2006), lingkungan belajar adalah segala sesuatu yang berhubungan dengan tempat proses pembelajaran dilaksanakan. Lingkungan mencakup dua hal utama, yaitu lingkungan fisik dan lingkungan sosial, kedua aspek lingkungan tersebut dalam proses pembelajaran harus saling mendukung. Lingkungan belajar siswa yang berpengaruh terhadap hasil belajar siswa terdiri dari lingkungan keluarga, lingkungan sekolah, dan lingkungan masyarakat (Slameto, 2003 dalam Hendrian, 2012).

$\mathrm{H}_{4}=$ Lingkungan belajar berpengaruh terhadap tingkat pemahaman akuntansi.

$\mathrm{H}_{8}=$ Perkembangan teknologi memperkuat hubungan antara lingkungan belajar terhadap tingkat pemahaman akuntansi.

\section{Perkembangan Teknologi}

Teknologi menurut Miarso (2007) adalah proses yang meningkatkan nilai tambah, proses tersebut menggunakan atau menghasilkan suatu produk yang tidak terpisah dari produk lain yang sudah ada, dan karena itu menjadi bagian integral dari suatu sistem (Indra, 2012).

\section{Tingkat Pemahaman Akuntansi}

Suwardjono (2005) menyatakan akuntansi sebagai seperangkat pengetahuan yang luas dan komplek. Akuntansi didefinisi dari dua sudut yaitu sebagai perangkat pengetahuan dan sebagai proses atau praktik. 
Menurut Budhiyanto dan Paskah (2004) dalam Hurmayanti (2011), tingkat pemahaman akuntansi mahasiswa dinyatakan dengan seberapa mengerti seorang mahasiswa terhadap apa yang sudah dipelajari yang dalam konteks ini mengacu pada mata kuliah akuntansi. Mahasiswa dapat menguasai atau memahami akuntansi apabila ilmu akuntansi yang sudah diperoleh dapat diterapkan dalam kehidupan bermasyarakat atau di dunia kerja.

Pemahaman akuntansi pada penelitian ini akan diukur dengan menggunakan nilai mata kuliah akuntansi yaitu Akuntansi Pengantar 1, Akuntansi Pengantar 2, Akuntansi Keuangan Menengah 1, Akuntansi Keuangan Menengah 2, Akuntansi Keuangan Lanjutan 1, Akuntansi Keuangan Lanjutan 2, Pengauditan 1, Pengauditan 2, dan Teori Akuntansi yang diadopsi dari skripsi Maryati (2012).

\section{METODA PENELITIAN}

\section{Populasi dan Sampel}

Populasi dalam penelitian ini adalah seluruh mahasiswa program studi akuntansi di UGM, STIE YKPN, UPN Veteran Yogyakarta, dan UAD. Penelitian ini menggunakan teknik pengambilan sampel nonprobability sampling berupa purposive sampling. Sampel ditentukan berdasarkan kriteria yaitu mahasiswa angkatan 2008/2009 jurusan akuntansi yang telah menempuh minimal 120 SKS dan telah mengambil matakuliah Akuntansi Pengantar 1, Akuntansi Pengantar 2, AKM 1, AKM2, AKL 1, AKL 2, Pengauditan 1, Pengauditan 2, dan Teori Akuntansi. Jenis data dalam penelitian ini adalah data primer yaitu data yang diperoleh dari responden melalui kuesioner.

\section{Definisi Operasional dan Pengukuran Variabel}

\section{Variabel Dependen (Y)}

Variabel dependen adalah variabel yang dipengaruhi oleh variabel lain. Variabel yang dipengaruhi adalah tingkat pemahaman akuntansi yang diukur berdasarkan perolehan nilai mata kuliah Akuntansi Pengantar 1, Akuntansi Pengantar 2, AKM 1, AKM 2, AKL 1, AKL 2, Pengauditan 1, Pengauditan 2, dan Teori Akuntansi. 


\section{Variabel Independen $(\mathbf{X})$}

\section{Kecerdasan Emosional}

Kecerdasan emosional dalam penelitian ini diukur menggunakan kuesioner yang berisi pertanyaan yang mencakup komponen-komponen kecerdasan emosional yaitu pengendalian diri, pengenalan diri, motivasi, empati, dan keterampilan sosial.

\section{Kecerdasan Spiritual}

Kecerdasan spiritual dalam penelitian ini diukur menggunakan kuesioner yang berisi pertanyaan yang berkaitan dengan keenam prinsip di dalam kecerdasan spiritual yaitu prinsip ketuhanan, prinsip kepercayaan, berjiwa kepemimpinan, berjiwa pembelajar, berorientasi masa depan, dan prinsip keteraturan.

\section{Perilaku Belajar}

Perilaku belajar dalam penelitian ini diukur menggunakan kuesioner yang komponen pertanyaannya mencakup kebiasaan belajar seseorang yaitu kebiasaan mengikuti pelajaran, kebiasaan membaca buku, kunjungan ke perpustakaan, dan kebiasaan menghadapi ujian.

\section{Lingkungan Belajar}

Variabel lingkungan belajar dalam penelitian ini diukur dengan kuesioner yang item pertanyaannya berkaitan dengan tiga lingkungan belajar yaitu lingkungan keluarga, lingkungan sekolah, dan lingkungan masyarakat.

\section{Variabel Pemoderasi $(Z)$}

Variabel pemoderasi merupakan variabel yang memperkuat hubungan antara variabel independen dengan variabel dependen. Variabel pemoderasi dalam penelitian ini adalah perkembangan teknologi yang diukur menggunakan kuesioner yang item pertanyaannya mencakup penggunaan teknologi dalam kegiatan belajar di lingkungan sekolah maupun penggunaan teknologi dalam kegiatan sehari-hari. 


\section{Teknik Analisis Data}

\section{Analisis Deskriptif}

Analisis statistik deskriptif digunakan untuk memberikan atau deskripsi suatu data yang dilihat dari nilai rata-rata (mean), deviasi standar, maksimum, minimum, dan range masing-masing variabel independen dan variabel dependen (Ghozali, 2011: 19).

\section{Uji Kualitas Data}

Uji validitas digunakan untuk mengukur sah atau valid tidaknya suatu kuesioner. Suatu kuesioner dikatakan valid jika pertanyaan pada kuesioner mampu untuk mengungkapkan sesuatu yang akan diukur oleh kuesioner. Pengujian ini menggunakan metoda Pearson correlation. Jika nilai signifikansi $<0,05$ maka data dikatakan valid (Ghozali, 2011: 52-53).

Reliabilitas adalah alat untuk mengukur suatu kuesioner yang merupakan indikator dari variabel atau konstruk. Kuesioner dikatakan realibel jika menunjukkan derajat konsistensi yang sama apabila diterapkan berulang-ulang pada kesempatan yang berlainan. Reliabilitas skala kecerdasan emosional diukur berdasarkan konsistensi internal yang perhitungannya dilakukan dengan teknik koefisien Cronbach alpha $(\alpha)$. Suatu konstruk atau variabel dikatakan reliabel jika memberikan nilai Cronbach alpha > 0,70 (Ghozali, 2011: 48).

\section{Uji Asumsi Klasik}

Uji normalitas bertujuan untuk menguji dalam model regresi, variabel pengganggu atau residual memiliki distribusi normal dan layak untuk diuji statistik maka diperlukan uji normalitas dengan menggunakan uji Kolmogorov-Smirnov (KS). Jika signifikansi (2-tailed) > 0,05 maka data berdistribusi normal, sedangkan jika signifikansi (2-tailed) $<0,05$ maka data tidak berdistribusi normal.

Uji Multikolinieritas bertujuan untuk menguji model regresi ditemukan adanya korelasi antar variabel bebas (independen). Jika VIF (variance inflation factor $)<10$ dan nilai tolerance > 0,1 maka tidak terjadi multikolinieritas antar variabel independennya (Ghozali, 2011: 105-106). 
Uji autokorelasi bertujuan mengetahui korelasi antara variabel pengganggu pada periode tertentu dengan variabel sebelumnya. Untuk menguji autokorelasi dengan menggunakan Durbin Watson test (DW). Jika angka DW di bawah -2 sampai +2 maka tidak ada korelasi. Jika di atas -2 maka ada autokorelasi negatif (Santoso, 2000 dalam Rahmawati, 2013).

Uji Heteroskedastisitas bertujuan menguji dalam model regresi terjadi ketidaksamaan variance dari residual satu pengamatan ke pengamatan yang lain. Cara untuk mendeteksi ada atau tidaknya heteroskedastisitas yaitu menggunakan uji Glejser. Jika nilai probabillitas signifikansinya di atas tingkat kepercayaan 0,05 maka dapat disimpulkan bahwa model regresi tidak mengandung adanya heteroskedastisitas (Ghozali, 2011: 139; 143).

\section{Uji Hipotesis}

Pengujian hipotesis bertujuan untuk peneliti menggunakan uji regresi berganda, uji MRA, dan uji Chow.

\section{Regresi berganda}

Analisis regresi berganda dilakukan untuk menguji hipotesis pertama, hipotesis kedua, hipotesis ketiga, dan hipotesis keempat. Persamaan regresinya sebagai berikut:

$$
\mathrm{Y}=\beta_{0}+\beta_{1} X_{1}+\beta_{2} X_{2}+\beta_{3} X_{3}+\beta_{4} X_{4}+e
$$

Keterangan:

$\begin{array}{ll}\mathrm{Y} & : \text { Tingkat Pemahaman Akuntansi } \\ \beta_{0} & : \text { Konstanta } \\ \beta_{1}-\beta_{4} & : \text { Koefisien regresi } \\ X_{1} & : \text { Kecerdasan Emosional } \\ X_{2} & : \text { Kecerdasan Spiritual } \\ X_{3} & : \text { Perilaku Belajar } \\ \mathrm{X}_{4} & : \text { Lingkungan Belajar } \\ \mathrm{e} & : \text { Kesalahan regresi }\end{array}$




\section{Moderated Regression Analysis (MRA)}

Uji MRA dilakukan untuk menguji hipotesis kelima, hipotesis keenam, hipotesis ketujuh, dan hipotesis kedelapan yang merupakan hipotesis yang berkaitan dengan variabel pemoderasi.

\section{Uji Chow}

Penelitian ini menggunakan uji Chow untuk menguji variabel moderasi pada hipotesis $5,6,7$, dan 8 .

\section{Kriteria Pengujian Hipotesis}

\section{a. Koefisien Determinasi}

Koefisien determinasi $\left(R^{2}\right)$ adalah sebuah koefisien yang menunjukkan persentase sebuah pengaruh variabel independen terhadap variabel dependen. Persentase tersebut menunjukkan seberapa besar variabel independen dapat menjelaskan variabel dependen. Nilai yang mendekati satu berarti variabelvariabel independen memberikan hampir semua informasi yang dibutuhkan untuk memprediksi variasi varibel dependen (Ghozali, 2011: 97).

\section{b. Uji F}

Uji F menunjukkan ada atau tidaknya semua variabel independen atau bebas yang dimasukkan dalam model mempunyai pengaruh terhadap variabel dependen (Ghozali, 2011: 98). Uji F dilakukan jika p-value > alpha maka hasil penelitian tidak berpengaruh. Sebaliknya, jika $p$-value < alpha maka hasil penelitian berpengaruh.

\section{c. Uji t}

Uji t digunakan untuk menunjukkan ada tidaknya pengaruh satu variabel independen secara individual dalam menerangkan variasi variabel dependen yaitu tingkat pemahaman akuntansi. Pengujian hipotesis dilakukan dengan menggunakan significance level $0,05(\alpha=5 \%)$. Jika $p$ - value > alpha maka hasil penelitian mendukung hipotesis nol dan menolak hipotesis alternatif. Jika nilai p-value < alpha maka hasil penelitian menolak hipotesis nol atau tidak dapat menolak hipotesis alternatif (Ghozali, 2011: 98-99). 


\section{PEMBAHASAN}

\section{Hasil Uji Asumsi Klasik}

\section{Uji Normalitas Data}

Hasil uji normalitas menunjukkan nilai signifikansi residual sebesar 0,306 $>0,05$. Berdasar hasil tersebut, dapat diketahui bahwa data berdistribusi normal.

\section{Uji Multikolinieritas}

Berdasar hasil pengujian multikolinieritas, diperoleh nilai tolerance untuk setiap variabel independen $\geq 0,10$ atau sama dengan niali VIF $\leq 10$. Berdasar hasil tersebut, dapat diketahui bahwa tidak terdapat multikolinieritas pada variabel independen.

\section{Uji Autokorelasi}

Berdasar hasil uji autokorelasi diperoleh persamaan Durbin-Watson test terletak pada nilai Durbin-Watson 1,627. Berdasar hasil tersebut, dapat diketahui dapat diartikan tidak ada autokorelasi.

\section{Uji Heteroskedastisitas}

Hasil pengujian heteroskedastisitas menunjukkan bahwa setiap variabel independen memiliki nilai signifikansi sebesar 1,00 dan dapat dikategorikan $>0,05$ maka tidak terjadi heteroskedastisitas.

\section{Hasil Uji Regresi}

a) Uji Regresi Berganda

Koefisien Determinasi

\section{Tabel 1}

Uji Koefisien Determinasi

\begin{tabular}{|l|c|c|c|c|c|}
\hline Model & $\mathbf{R}$ & $\boldsymbol{R}$ Square & Adjusted $\boldsymbol{R}^{\mathbf{2}}$ & $\begin{array}{c}\text { Std. Error of the } \\
\text { estimate }\end{array}$ & Durbin-Watson \\
\hline 1 & $.201^{\mathrm{a}}$ & .040 & .019 & 3.992 & 1.627 \\
\hline
\end{tabular}

Sumber: Data primer, diolah (2013) 
Berdasar tabel 1 dapat diketahui bahwa nilai $\mathrm{R}$ square sebesar 0,040 atau 4\% variabel independen mampu menjelaskan tingkat pemahaman akuntansi dan sisanya 96\% dijelaskan oleh variabel lain di luar penelitian ini.

\section{Uji F}

\section{Tabel 2}

Uji F

\begin{tabular}{|c|l|r|l|l|l|}
\hline Model & Sum of Squares & $\boldsymbol{d} f$ & Mean Square & $\boldsymbol{F}$ & Sig. \\
\hline $\begin{array}{c}1 \\
\text { Regression }\end{array}$ & 117.650 & 4 & 29.412 & 1.846 & $.122^{\mathrm{a}}$ \\
\cline { 2 - 6 } & 2788.678 & 175 & 15.935 & & \\
\cline { 2 - 6 } Residual & 2906.328 & 179 & & & \\
\hline
\end{tabular}

Sumber: Data primer, diolah (2013)

Tabel 2 menunjukkan nilai $\mathrm{F}$ sebesar 1,846 dengan nilai signifikansi 0,122 yang artinya tidak adanya pengaruh secara simultan antara variabel independen dengan variabel dependen karena 0,122 >0,05.

\section{Uji t}

\section{Tabel 3}

Uji t

\begin{tabular}{|c|c|c|c|c|c|c|c|}
\hline & \multicolumn{2}{|c|}{$\begin{array}{l}\text { Unstandardized } \\
\text { Coefficients }\end{array}$} & \multirow{2}{*}{\begin{tabular}{|l|}
$\begin{array}{c}\text { Standardized } \\
\text { Coefficients }\end{array}$ \\
Beta \\
\end{tabular}} & \multirow{2}{*}{$t$} & \multirow{2}{*}{ Sig. } & \multicolumn{2}{|c|}{$\begin{array}{c}\text { Collinearity } \\
\text { Statistics }\end{array}$} \\
\hline & $\boldsymbol{B}$ & Std.Error & & & & Tolerance & VIF \\
\hline 1 (Constant) & 29.749 & 4.235 & & 7.024 & .000 & & \\
\hline Kecerdasan Emosional & .005 & .044 & .011 & .115 & .908 & .628 & 1.593 \\
\hline Kecerdasan Spiritual & .101 & .065 & .152 & 1.564 & .120 & .584 & 1.714 \\
\hline Perilaku Belajar & .084 & .049 & .145 & 1.709 & .089 & .767 & 1.304 \\
\hline Lingkungan Belajar & -.146 & .085 & .155 & -1.711 & .089 & .667 & 1.500 \\
\hline
\end{tabular}

Sumber: Data primer, diolah (2013)

Berdasar tabel 3 dapat diketahui bahwa nilai signifikansi variabel kecerdasan emosional terhadap tingkat pemahaman akuntansi menunjukkan nilai 0,908 >0,05, 
sehingga dapat disimpulkan bahwa kecerdasan emosional tidak berpengaruh terhadap tingkat pemahaman akuntansi, yang berarti hipotesis pertama tidak dapat diterima. Hal ini dikarenakan memiliki kecerdasan emosi yang tinggi saja tidak menjamin seorang mahasiswa akan mempunyai kesempatan untuk mempelajari kecakapan emosi yang penting untuk pembelajarannya guna mendapatkan prestasi yang tinggi (Goleman, 2005: 39).

Variabel kecerdasan spiritual menunjukkan nilai signifikansi sebesar 0,120 > 0,05, sehingga dapat disimpulkan bahwa kecerdasan spiritual tidak berpengaruh terhadap tingkat pemahaman akuntansi, yang berarti hipotesis kedua tidak dapat diterima. Hal ini dikarenakan kecerdasan spiritual diukur berdasarkan beberapa prinsip dan tidak semua prinsip tersebut dimiliki oleh seorang mahasiswa. Seperti ketidakpercayaan diri terhadap kemampuan menyelesaikan setiap masalah yang dimiliki. Hasil penelitian ini mendukung penelitian Yani (2012), pada penelitian tersebut kecerdasan spiritual tidak berpengaruh terhadap pemahaman akuntansi dikarenakan banyak di antara mahasiswa melupakan hubungannya dengan Tuhan YME yang akhirnya mempengaruhi dalam belajar akuntansi, seperti tidak ada kejujuran dalam belajar, tidak berperilaku sesuai norma, dan tidak dapat menerima pendapat dari orang lain atas kekurangan dan kelemahan dirinya.

Variabel perilaku belajar menunjukkan nilai signifikansi sebesar 0,089> 0,05, sehingga dapat disimpulkan bahwa perilaku belajar tidak berpengaruh terhadap tingkat pemahaman akuntansi, yang berarti hipotesis ketiga tidak dapat diterima. Hal ini dikarenakan kebanyakan mahasiswa sulit memusatkan perhatiannya saat belajar, waktu luangnya jarang sekali dimanfaatkan dengan membaca, dan waktu belajar yang tidak disiplin. Hasil penelitian mendukung penelitian Maryati (2012) yang menyatakan bahwa perilaku belajar tidak berpengaruh terhadap tingkat pemahaman akuntansi karena waktu belajar yang tidak teratur dan kebiasaan belajar yang kurang baik.

Nilai signifikansi untuk variabel lingkungan belajar adalah 0,089 > 0,05, sehingga dapat diketahui bahwa lingkungan belajar tidak berpengaruh terhadap tingkat pemahaman akuntansi, yang berarti hipotesis keempat tidak dapat diterima. Hal ini dikarenakan lingkungan belajar baik itu lingkungan keluarga, lingkungan 
sekolah, dan lingkungan masyarakat tidak secara keseluruhan mendukung. Seperti lingkungan belajar di universitas yang suasana kelasnya tidak kondusif dan kurang terjaga kebersihannya. Dapat juga dikarenakan beberapa mahasiswa dapat tetap fokus pada materi pelajarannya walaupun kondisi lingkungan belajarnya tidak cukup baik. Lingkungan belajar berkaitan erat dengan interaksi kepada orang-orang di sekitar kita. Interaksi selalu berhubungan dengan komunikasi. Seorang mahasiswa yang berada pada lingkungan belajar yang baik tidak dapat memperoleh prestasi yang baik jika tidak aktif dalam komunikasi dengan anggota lingkungan. Komunikasi merupakan penyampaian informasi, pesan, dan atau gagasan dengan cara-cara tertentu yang melibatkan upaya membangun hubungan kolaboratif antar individu atau kelompok, untuk saling memahami dan menemukan solusi bersama (Sulistami, 2006: 123).

\section{b) Uji MRA}

Tabel 4

Hasil Pengujian MRA

\begin{tabular}{|c|c|c|c|}
\hline \multicolumn{2}{|r|}{ Persamaan } & Nilai F (Sig.) & $R$ Square \\
\hline 1 & $\mathrm{TPA}=+\beta 1 . \mathrm{KE}+\mathrm{e}$ & \multirow{2}{*}{1,606} & \multirow{3}{*}{$\begin{array}{l}\mathrm{R}^{2} \text { old } \\
0,009\end{array}$} \\
\hline & $\mathrm{TPA}=32,315+0,045 \mathrm{KE}+\mathrm{e}$ & & \\
\hline & 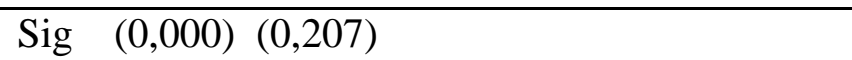 & 0,207 & \\
\hline \multirow[t]{3}{*}{2} & $\mathrm{TPA}=+\beta 1 . \mathrm{KE}+\beta 2 . \mathrm{PT}+\mathrm{e}$ & \multirow{2}{*}{0,889} & \multirow{3}{*}{$\begin{array}{r}R^{2} \text { new } \\
0,010\end{array}$} \\
\hline & $\mathrm{TPA}=31,068+0,040 \mathrm{KE}+0,023 \mathrm{PT}+\mathrm{e}$ & & \\
\hline & 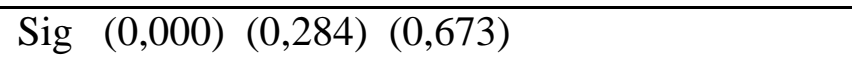 & 0,413 & \\
\hline \multirow[t]{3}{*}{3} & $\mathrm{TPA}=+\beta 1 . \mathrm{KE}+\beta 2 . \mathrm{PT}+\beta 3 . \mathrm{KE} * \mathrm{PT}+\mathrm{e}$ & \multirow{2}{*}{0,912} & \multirow{3}{*}{$\begin{array}{r}R^{2} \text { new } \\
0,015\end{array}$} \\
\hline & TPA $=-7,485+0,433 \mathrm{KE}+0,535 \mathrm{PT}-0,005 \mathrm{KE} * \mathrm{PT}+\mathrm{e}$ & & \\
\hline & \begin{tabular}{|llll} 
Sig $(0,851)$ & $(0,284)$ & $(0,311)$ & $(0,329)$
\end{tabular} & 0,437 & \\
\hline \multirow[t]{3}{*}{4} & $\mathrm{TPA}=+\beta 1 . \mathrm{KS}+\mathrm{e}$ & \multirow{2}{*}{2,564} & \multirow{3}{*}{$\begin{array}{l}\mathrm{R}^{2} \text { old } \\
0,014\end{array}$} \\
\hline & $\mathrm{TPA}=30,306+0,080 . \mathrm{KS}+\mathrm{e}$ & & \\
\hline & Sig $(0,000)(0,111)$ & 0,111 & \\
\hline \multirow[t]{2}{*}{5} & $\mathrm{TPA}=+\beta 1 . \mathrm{KS}+\beta 2 . \mathrm{PT}+\mathrm{e}$ & \multirow{2}{*}{1,308} & \multirow{2}{*}{$\mathrm{R}^{2}$ new } \\
\hline & $\mathrm{TPA}=29,627+0,075 . \mathrm{KS}+0,014 \mathrm{PT}+\mathrm{e}$ & & \\
\hline
\end{tabular}




\begin{tabular}{|c|c|c|c|}
\hline & \begin{tabular}{|llll} 
Sig & $(0,000)$ & $(0,160)$ & $(0,797)$
\end{tabular} & 0,273 & 0,015 \\
\hline \multirow[t]{3}{*}{6} & $\mathrm{TPA}=+\beta 1 . \mathrm{KS}+\beta 2 . \mathrm{PT}+\beta 3 . \mathrm{KS} * \mathrm{PT}+\mathrm{e}$ & & \multirow{3}{*}{$\begin{array}{r}\mathrm{R}^{2} \text { new } \\
0,015\end{array}$} \\
\hline & $\begin{array}{l}\text { TPA }=18,189+0,217 \mathrm{KS}+0,165 \mathrm{PT}- \\
0,002 \mathrm{KS} * \mathrm{PT}+\mathrm{e}\end{array}$ & 0,891 & \\
\hline & 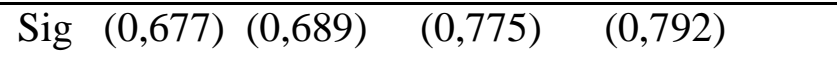 & 0,447 & \\
\hline \multirow[t]{3}{*}{7} & $\mathrm{TPA}=+\beta 1 . \mathrm{PB}+\mathrm{e}$ & \multirow{2}{*}{3,108} & \multirow{3}{*}{$\begin{array}{l}\mathrm{R}^{2} \text { old } \\
0,017\end{array}$} \\
\hline & TPA $=32,776+0,076 \mathrm{~PB}+\mathrm{e}$ & & \\
\hline & $\begin{array}{lll}\text { Sig } & (0,000) \quad(0,080)\end{array}$ & 0,080 & \\
\hline \multirow[t]{3}{*}{8} & $\mathrm{TPA}=+\beta 1 . \mathrm{PB}+\beta 2 . \mathrm{PT}+\mathrm{e}$ & \multirow{2}{*}{1,584} & \multirow{3}{*}{$\begin{array}{r}\mathrm{R}^{2} \text { new } \\
0,018\end{array}$} \\
\hline & $\mathrm{TPA}=31,866+0,073 \mathrm{~PB}+0,014 . \mathrm{PT}+\mathrm{e}$ & & \\
\hline & \begin{tabular}{|llll} 
Sig & $(0,000)$ & $(0,113)$ & $(0,785)$
\end{tabular} & 0,208 & \\
\hline \multirow[t]{3}{*}{9} & $\mathrm{TPA}=+\beta 1 . \mathrm{PB}+\beta 2 . \mathrm{PT}+\beta 3 . \mathrm{PB} * \mathrm{PT}+\mathrm{e}$ & \multirow{2}{*}{1,651} & \multirow{3}{*}{$\begin{array}{r}\mathrm{R}^{2} \text { new } \\
0,027\end{array}$} \\
\hline & $\mathrm{TPA}=0,982+0,680 \mathrm{~PB}+0,422 \mathrm{PT}-0,008 \mathrm{~PB} * \mathrm{PT}+\mathrm{e}$ & & \\
\hline & \begin{tabular}{|llll} 
Sig $(0,967)$ & $(0,140)$ & $(0,176)$ & $(0,185)$
\end{tabular} & 0,179 & \\
\hline \multirow[t]{3}{*}{10} & $\mathrm{TPA}=+\beta 1 . \mathrm{LB}+\mathrm{e}$ & \multirow{2}{*}{0,045} & \multirow{3}{*}{$\begin{array}{l}\mathrm{R}^{2} \mathrm{old} \\
0,000\end{array}$} \\
\hline & $\mathrm{TPA}=37,154-0,015 \mathrm{LB}+\mathrm{e}$ & & \\
\hline & $\begin{array}{lll}\text { Sig } & (0,000) & (0,833)\end{array}$ & 0,833 & \\
\hline \multirow[t]{3}{*}{11} & $\mathrm{TPA}=+\beta 1 . \mathrm{LB}+\beta 2 . \mathrm{PT}+\mathrm{e}$ & \multirow{2}{*}{0,459} & \multirow{3}{*}{$\begin{array}{r}\mathrm{R}^{2} \text { new } \\
0,005\end{array}$} \\
\hline & $\mathrm{TPA}=34,339-0,041 \mathrm{LB}+0,051 . \mathrm{PT}+\mathrm{e}$ & & \\
\hline & 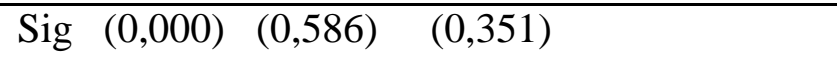 & 0,633 & \\
\hline \multirow[t]{3}{*}{12} & $\mathrm{TPA}=+\beta 1 . \mathrm{LB}+\beta 2 . \mathrm{PT}+\beta 3 . \mathrm{LB} * \mathrm{PT}+\mathrm{e}$ & \multirow{2}{*}{0,851} & \multirow{3}{*}{$\begin{array}{r}\mathrm{R}^{2} \text { new } \\
0,014\end{array}$} \\
\hline & TPA=76,261-1,074LB-0,499PT+0,014LB*PT+e & & \\
\hline & Sig $(0,022) \quad(0,187)$ & 0,468 & \\
\hline
\end{tabular}

Sumber: Data primer, diolah (2013) 


\section{c) Uji Chow}

\section{Tabel 5}

\section{Perhitungan Uji Chow}

\begin{tabular}{|c|c|c|c|c|c|}
\hline \multirow{2}{*}{\multicolumn{2}{|c|}{ Persamaan }} & $\bar{A}$ & $\mathrm{~B}$ & $\mathrm{~A} / \mathrm{B}$ & \\
\hline & & $\mathrm{R}^{2}$ new - $\mathrm{R}^{2}$ old $/ 1$ & $1-R^{2}$ new $/ n-k$ & $\mathrm{~F}$ hitung & F tabel \\
\hline 1 & 5 & $0,010-0,009 / 1$ & $(1-0,010) /(180-4)$ & 0,167 & 2,422 \\
\hline 1 & 9 & $0,015-0,009 / 1$ & $(1-0,015) /(180-5)$ & 1,000 & 2,422 \\
\hline 2 & 6 & $0,015-0,014 / 1$ & $(1-0,015) /(180-4)$ & 0,167 & 2,422 \\
\hline 2 & 10 & $0,015-0,014 / 1$ & $(1-0,015) /(180-5)$ & 0,167 & 2,422 \\
\hline 3 & 7 & $0,018-0,017 / 1$ & $(1-0,018) /(180-4)$ & 0,167 & 2,422 \\
\hline 3 & 11 & $0,027-0,017 / 1$ & $(1-0,027) /(180-5)$ & 1,667 & 2,422 \\
\hline 4 & 8 & $0,005-0,000 / 1$ & $(1-0,005) /(180-4)$ & 0,833 & 2,422 \\
\hline 4 & 12 & $0.014-0.000 / 1$ & $(1-0,014) /(180-5)$ & 2,333 & 2.422 \\
\hline
\end{tabular}

Sumber: Data primer, diolah (2013)

Berdasar tabel 5, persamaann 1, 5, 9 untuk menguji hipotesis kelima, persamaan 2, 6, 10 untuk menguji hipotesis keenam, persamaan 3, 7, 11 untuk menguji hipotesis ketujuh, dan persamaan 4, 8, 12 untuk menguji hipotesis kedelapan dengan membandingkan regresi pada tiap persamaan. Persamaan 1, 5, 9 diperoleh nilai signifikansi $\beta_{2}=0(0,311>0,05)$ dan $\beta_{3}=0(0,329>0,05)$ atau tidak ada yang signifikan, maka dapat disimpulkan bahwa hipotesis kelima yang menyatakan perkembangan teknologi dapat memperkuat hubungan antara kecerdasan emosional terhadap tingkat pemahaman akuntansi, tidak dapat diterima. Hasil ini diperkuat dengan hasil perhitungan uji Chow yang menunjukkan nilai $\mathrm{F}$ hitung pada persamaan 1 dan 5 yaitu $0,167<\mathrm{F}$ tabel 2,422 dan persamaan 1 dan 9 yaitu $1,000<\mathrm{F}$ tabel 2,422, yang berarti perkembangan teknologi bukan merupakan variabel pemoderasi.

Persamaan 2, 6, 10 juga diperoleh nilai signifikansi $\beta_{2}=0(0,775>0,05)$ dan $\beta_{3}=0(0,792>0,05)$ atau tidak ada yang signifikan, maka dapat disimpulkan bahwa hipotesis keenam menyatakan perkembangan teknologi dapat memperkuat hubungan antara kecerdasan spiritual terhadap tingkat pemahaman akuntansi, tidak 
dapat diterima. Hasil ini diperkuat dengan hasil perhitungan uji Chow yang menunjukkan nilai $F$ hitung pada persamaan 2 dan 6 yaitu $0,167<F$ table 2,422 dan persamaan 2 dan 10 yaitu $0,167<\mathrm{F}$ table 2,422 . Hal ini berarti perkembangan teknologi bukan merupakan variabel pemoderasi.

Persamaan 3, 7, 11 diperoleh nilai signifikansi $\left.\beta_{2}=0(0,176)>0,05\right)$ dan $\beta_{3}=0$ $(0,185>0,05)$ atau keduanya tidak signifikan, maka apdat disimpulkan bahwa hipotesis ketujuh yang menyatakan bahwa perkembangan teknologi dapat memperkuat hubungan antara perilaku belajar terhadap tingkat pemahaman akuntansi, tidak dapat diterima. Hasil ini diperkuat dengan hasil perhitungan uji Chow yang menunjukkan nilai $\mathrm{F}$ hitung pada persamaan 3 dan 7 yaitu $0,167<\mathrm{F}$ tabel 2,422 dan persamaan 3 dan 11 yaitu 1,667 $<\mathrm{F}$ tabel 2,422, yang berarti perkembangan teknologi bukan merupakan variabel pemoderasi.

Persamaan 4, 8, 12 diperoleh nilai signifikansi $\beta_{2}=0(0.252>0,05)$ dan $\beta_{3}=0$ $(0,203>0,05)$ atau keduanya tidak signifikan, maka dapat disimpulkan bahwa hipotesis kedelapan menyatakan bahwa perkembangan teknologi dapat memperkuat hubungan antara perilaku belajar terhadap tingkat pemahaman akuntansi, tidak dapat diterima. Hasil ini diperkuat dengan hasil perhitungan uji Chow yang menunjukkan nilai $\mathrm{F}$ hitung pada persamaan 4 dan 8 yaitu $0,833<\mathrm{F}$ tabel 2,422 dan persamaan 4 dan 12 yaitu 2,333 $<\mathrm{F}$ tabel 2,422, yang berarti perkembangan teknologi bukan merupakan variabel pemoderasi.

\section{SIMPULAN}

a) Hasil hipotesis pertama, kecerdasan emosional tidak berpengaruh terhadap tingkat pemahaman akuntansi.

b) Hasil hipotesis kedua, kecerdasan spiritual tidak berpengaruh terhadap tingkat pemahaman akuntansi.

c) Hasil hipotesis ketiga, perilaku belajar tidak berpengaruh terhadap tingkat pemahaman akuntansi.

d) Hasil hipotesis keempat, lingkungan belajar tidak berpengaruh terhadap tingkat pemahaman akuntansi.

e) Hasil hipotesis kelima, perkembangan teknologi tidak memperkuat hubungan antara kecerdasan emosional terhadap tingkat pemahaman akuntansi. 
f) Hasil hipotesis keenam, perkembangan teknologi tidak memperkuat hubungan antara kecerdasan spiritual terhadap tingkat pemahaman akuntansi.

g) Hasil hipotesis ketujuh, perkembangan teknologi tidak memperkuat hubungan antara perilaku belajar terhadap tingkat pemahaman akuntansi.

h) Hasil hipotesis kedelapan, perkembangan teknologi tidak memperkuat hubungan antara lingkungan belajar terhadap tingkat pemahaman akuntansi.

i) Hasil perhitungan dengan uji Chow menunjukkan bahwa perkembangan teknologi bukan merupakan variabel pemoderasi untuk keseluruhan variabel independen.

\section{DAFTAR PUSTAKA}

Agustian, Ary Ginanjar. 2005. Emotional Spiritual Quotient. Jakarta: Penerbit Arga.

Aziza, Nurna, dan Rissyo Melandy RM. 2006. "Pengaruh Kecerdasan Emosional terhadap Tingkat Pemahaman Akuntansi, Kepercayaan Diri sebagai Variabel Pemoderasi”Simposium Nasional Akuntansi 9 Padang (Agustus). hal. 17-19.

Bachrintania, Andita Faizatul. 2012. Pengaruh Pemanfaatan Teknologi Informasi dan Komunikasi dalam Pembelajaran Ekonomi terhadap Motivasi dan Prestasi Belajar Ekonomi Siswa Kelas $X$ di SMAN 3 Yogyakarta. Skripsi. Yogyakarta: Universitas Negeri Yogyakarta.

Ghozali, Imam. 2011. Aplikasi Analisis Multivariate dengan Program SPSS. Edisi Kelima. Semarang: BP-UNDIP.

Goleman, Daniel. 2005. Working with Emotional Intelligence. Jakarta: PT Gramedia Pustaka Utama.

Indriantoro, Nur, dan Bambang Supomo. 1999. Metodologi Penelitian Bisnis untuk Akuntansi dan Manajemen. Yogyakarta: BPFE.

Lembaga Administrasi Negara. 2009. Modul Pendidikan dan Pelatihan Prajabatan Golongan III. Didapatkan: <www.google.com> [30 Maret 2013]. 
Maryati, Sri. 2012. Pengaruh Motivasi Belajar, Gaya Belajar, dan Perilaku Belajar terhadap Tingkat Pemahaman Akuntansi. Skripsi. Yogyakarta: Universitas Ahmad Dahlan.

Miarso. 2007. Didapatkan: http://www.aingindra.com/2012/11/definisiteknologi.html [ 25 April 2013].

Nurmalia. Erlina. 2012. Pengaruh Fasilitas dan Lingkungan Belajar terhadap Prestasi Belajar Siswa Kelas XI IPS MAN Malang 1. Skripsi. Malang: UIN Maulana Malik Ibrahim.

Rachmi, Filia. 2010. Pengaruh Kecerdasan Emosional, Kecerdasan Spirital dan Perilaku Belajar terhadap Tingkat Pemahaman Akuntansi. Skripsi. Yogyakarta: Universitas Gajah Mada.

Rahmawati, Bintari. 2013. Pengaruh Kecerdasan Intelektual terhadap Tingkat Pemahaman Akuntansi dengan Motivasi, Pengendalian Diri, Komunikasi, Lingkungan Belajar sebagai Variabel Pemoderasi. Skrpsi. Yogyakarta: UAD.

Sabinta, Vega. 2010. Pengaruh Penggunaan Teknologi Informasi dan Kepercayaan Sistem Informasi terhadap Kinerja Individual. Skripsi. Yogyakarta: UAD.

Slameto. 2003. Didapatkan: http://hendriansdiamond.blogspot.com/2012.

Sulistami, Ratna D, dan Erlinda Manaf Mahdi. 2006. Universal Intelligence. Jakarta: PT Gramedia Pustaka Utama.

Suwardjono. 2005. Teori Akuntansi Perekayasaan Pelaporan Keuangan. Yogyakarta: BPFE.

Tim Penyusun Kamus Pusat Bahasa, 2002, Kamus Besar Bahasa Indonesia, Jakarta: Balai Pustaka.

Trisniwati, Eka Indah. 2003. Pengaruh Kecerdasan Emosional terhadap Tingkat Pemahaman Akuntansi. Skripsi. Yogyakarta: UPN.

Utama, Arya. 2010. Pengertian Kecerdasan Emosional. Didapatkan: www.google.com [05 April 2013]. 
Yani, Fitri. 2012. Pengaruh Kecerdasan Intelektual, Kecerdasan Emosional dan Kecerdasan Spiritual terhadap Pemahaman Akuntansi. Skripsi. Pekanbaru: Universitas Riau.

Yuniani, Anggun. 2010. Pengaruh Kecerdasan Emosional terhadap Tingkat Pemahaan Akuntansi. Skripsi.Semarang: Universitas Diponegoro.

Zohar, Danah dan Ian Marshall. 2001. SQ: Memanfaatkan Kecerdasan Spiritual dalam Berpikir Integralistik dan Holistik untuk Memaknai Kehidupan. Bandung: Mizan Pustaka. 